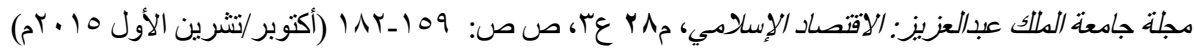 DOI: 10.4197 / Islec. 28-3.4
}

\section{دليل ضهمان جودة الأداء للمصيارف الإسلامية*}

\author{
عدنان عبدالله محمد عويضية \\ أستاذ مساعد في الاقتصياد والمصيارف الإسبلامية \\ جامعة زايد - الإمارات العربية المتحدة
}

المستخلص. يهدف هذا البحث إلى وضع اللبنات الأولى نحو بناء دليل

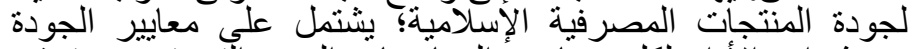

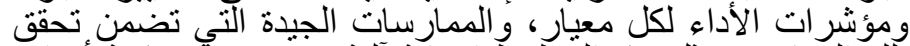

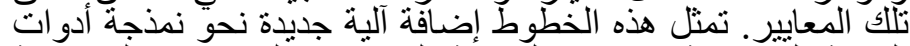

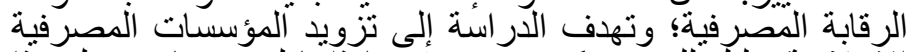

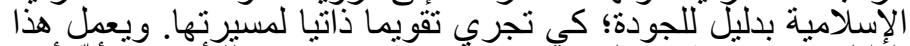

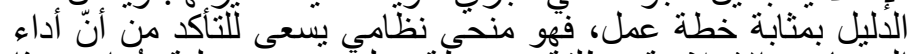

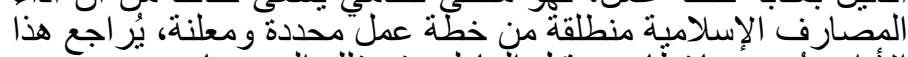
الأداء ويُحسن بانتظام من قبل العاملين في تللك المؤسسات.

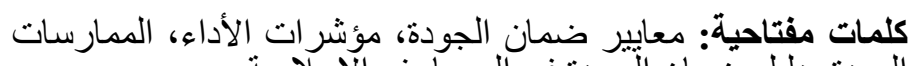
الجيدة، دليل ضُّمان الجودة في المصارف الإسلامية.

* هذا البحث مدعوم من قبل عمادة البحث العلمي ـ جامعة الزرقاء ـ الأردن. يشكر الباحث الجهة الباعمة عدلى ذللى، و والمحكمين على ملاحظظّاتهم ألقيمة. 109 


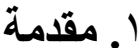

تعد ظاهرة البنوك الإسلامية الحدث الأبرز على صعيد الساحة المصرفية العربية والإسلامية، بل والدولية في الربع الأخير من القرن الماضي وذلإنك للفرق

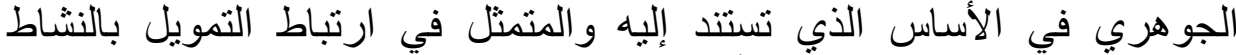

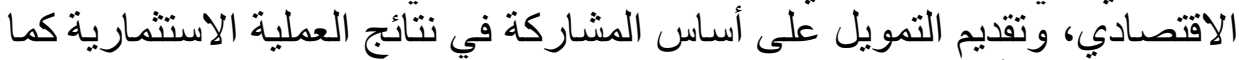

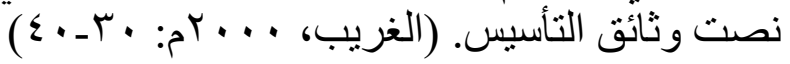

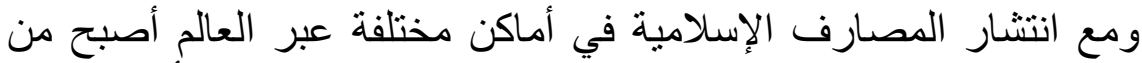

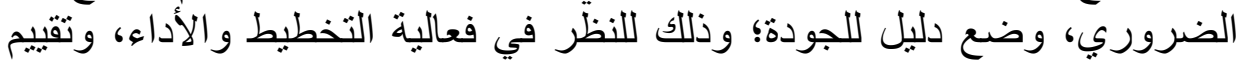

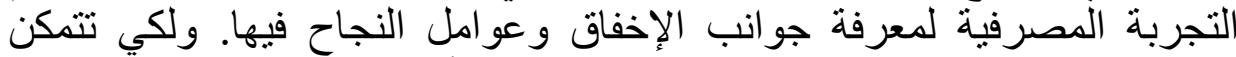

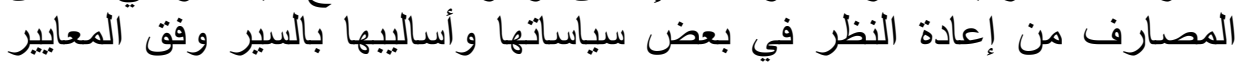
المنشودة؛ كانت هذه الدر اسة.

وحيث أنّ المصارف الإسلامية مؤسسات ألزمت نفسها بخصوصية الالتز ام إمهائ

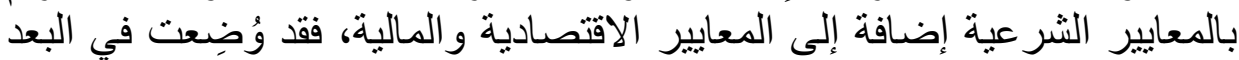

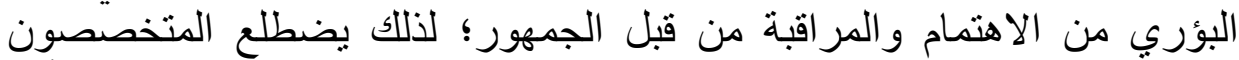

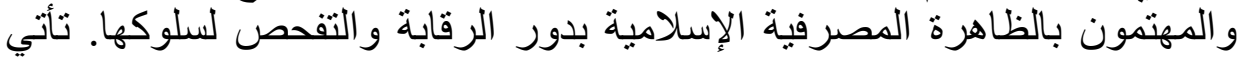

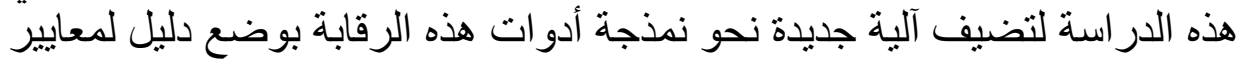

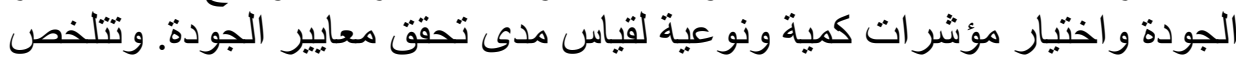

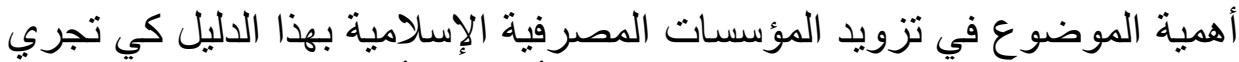

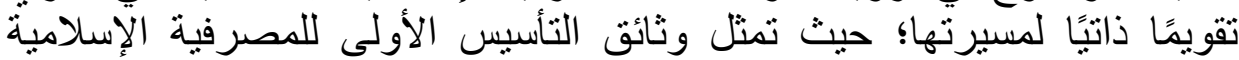

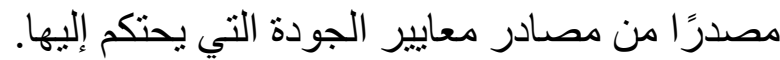

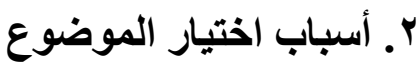

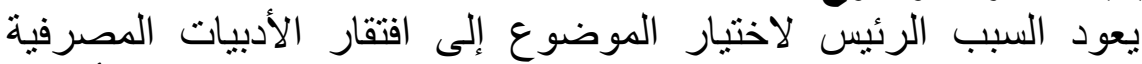

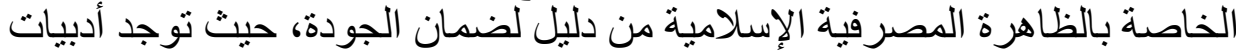

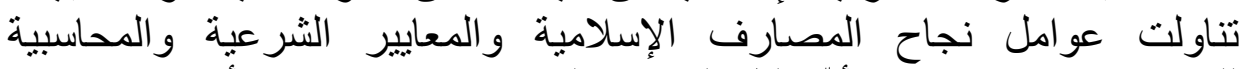

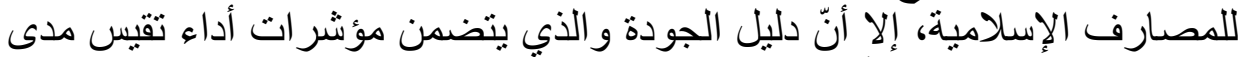

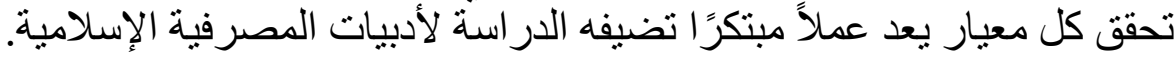

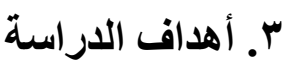

يهدف البحث إلى وضع اللبنات الأولى نحو بناء دليل لجودة المنتجات

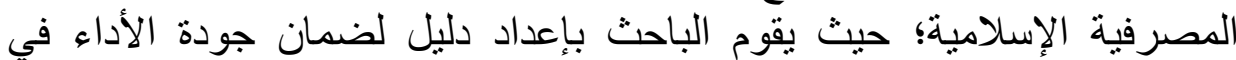

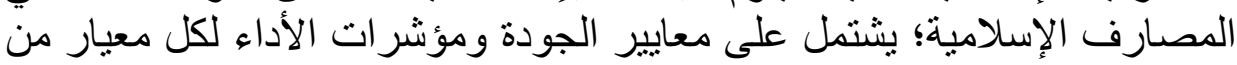
تللك المعايير ، و الممارسات الجيدة التي تضمن تحقق معايير الجودة. ع ـ مشكلة الدراسة 
تتحدد مشكلة الدر اسة في التساؤلات التالية:

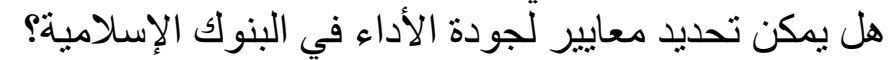
هل يمكن تحديد مؤشر ات للأداء في البنوك الإسلامية؛

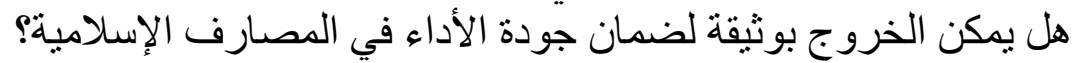

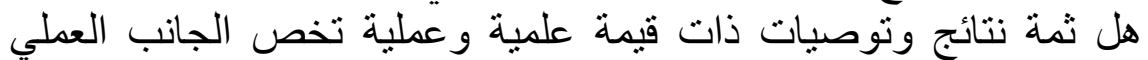

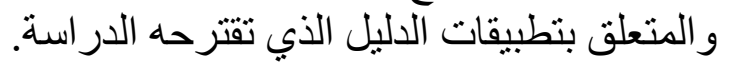

استنادًا لما تقدم في مشكلة الدر اسة و أهدافها، تمت صياغة فرضيات الدر اسة التالية: هـ فرضيات الدراسة - يمكن بناء دليل لجودة الأداء قابلة للقياس تمكن المصارف الإسلامية من تقييم أدائها ذاتيًا. - يعمل الدليل المنشود كمرجع ذاتي للارتقاء بجودة الأداء للمصارف الإسلامية،

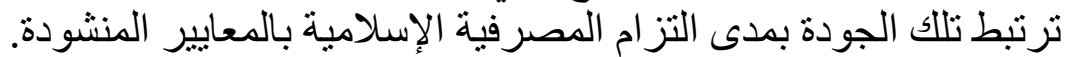

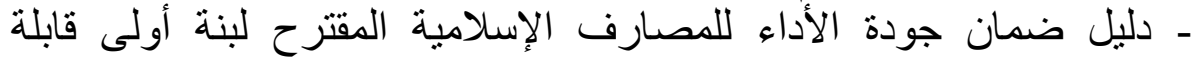

للتطوير بإضافة معايير جديدة.

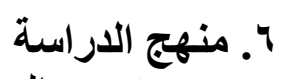

يستخدم البحث المنهج الاستقرائي لأدبيات المصرفية الإستامية ليجمع الإنية

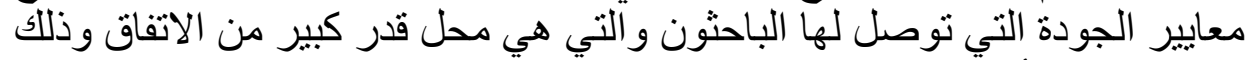

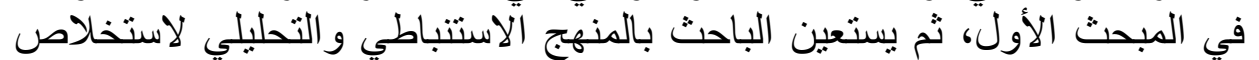

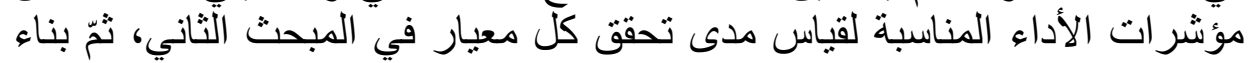

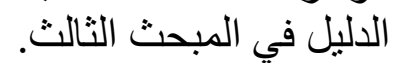

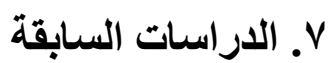
فيما يلي أهم الدر اسات السابقة و التي تتصل بشكل مباشر بموضوع البحث: ـ معايير "هيئة المراجعة والمحاسبة للمؤسسات المصرفية الإسبلامية"

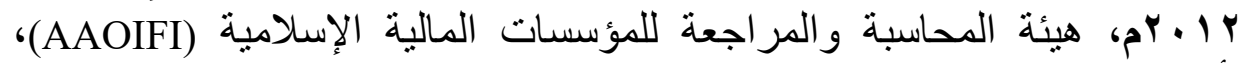

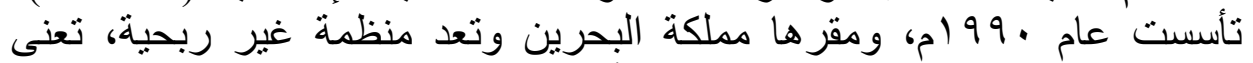

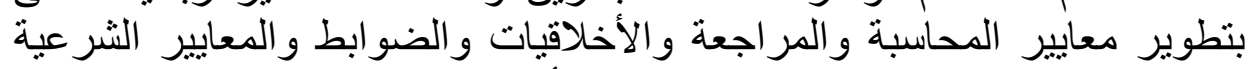

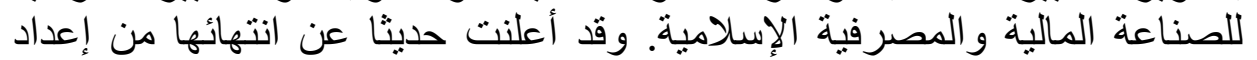

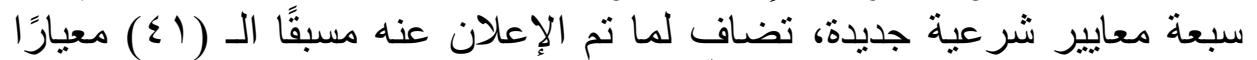

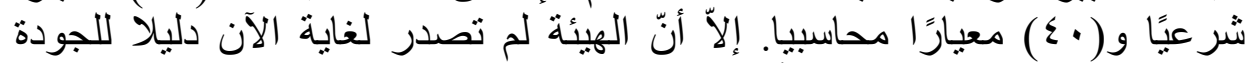
يشتمل على معايير ومؤشر ات أداء وممارسات جيدة تفيد منه البنوك الإسلامية. 
ـ دراسة (عبدالستار أبو غدة، ومحمد علي القري) "تصنيف المصارف

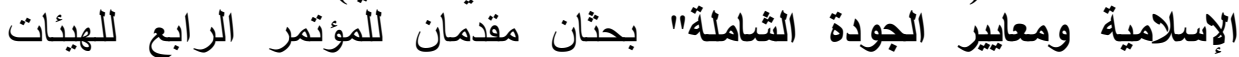

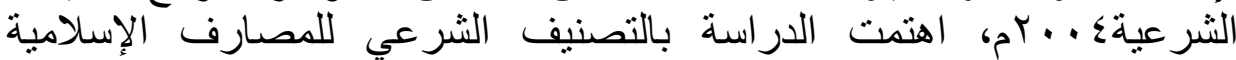

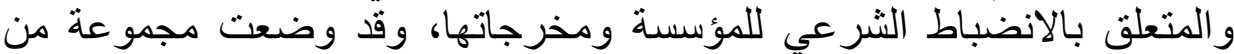

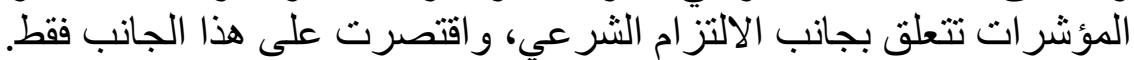

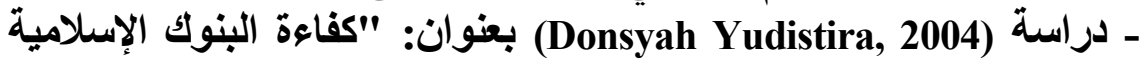

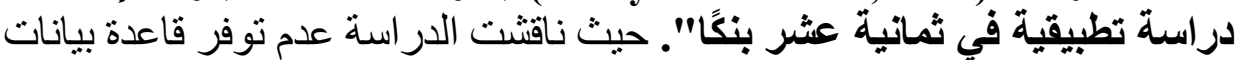

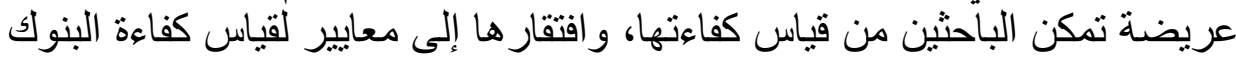
الإسلامية. وطرحت تساؤلات تتعلق بماهية المعايير المقترحة لقياس كفاءتهاب ثنّة

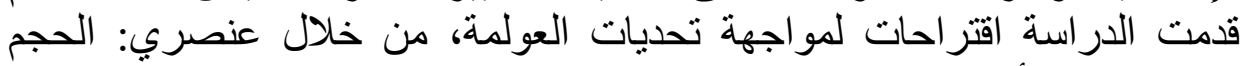
والاندماج. إلا أن الدر اسة لم تخرجة لهر لنا دليلا لمعايير الجودة.

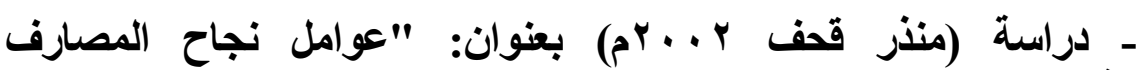

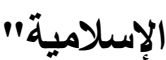

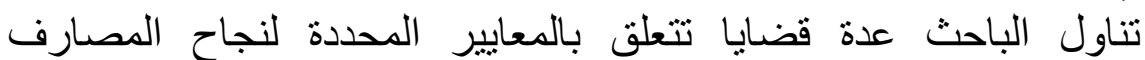

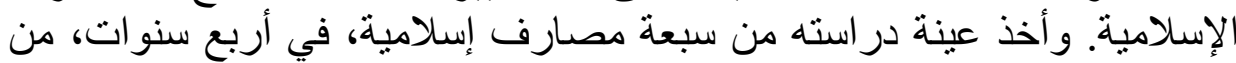

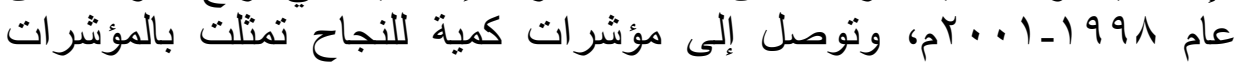

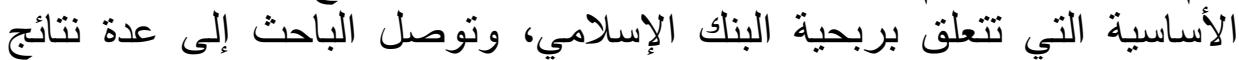

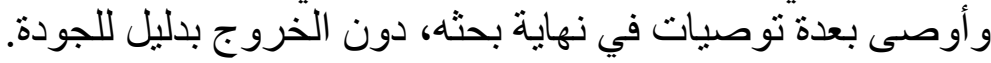

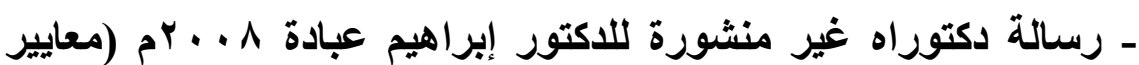

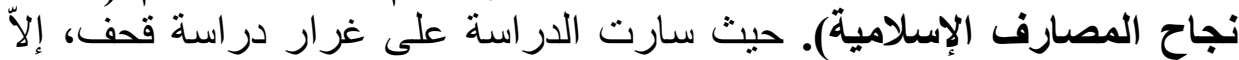

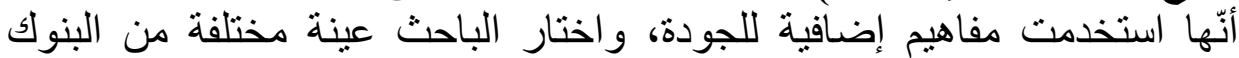

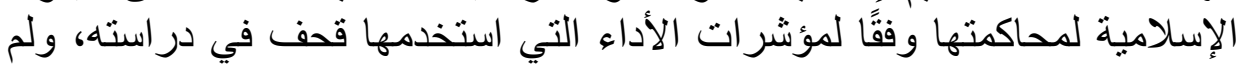

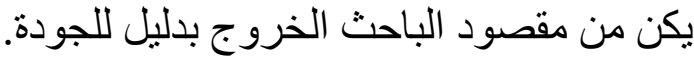

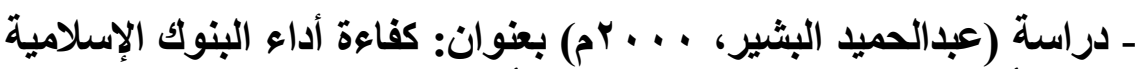

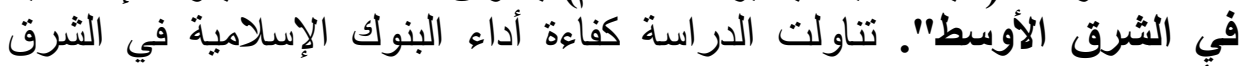

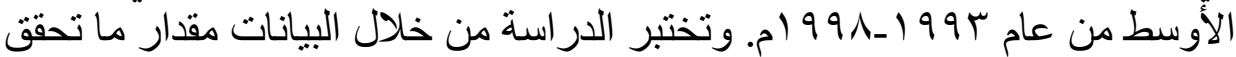

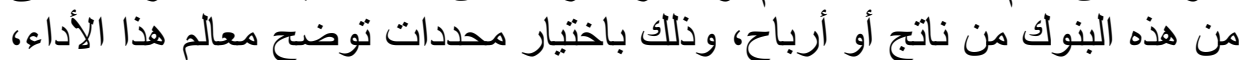

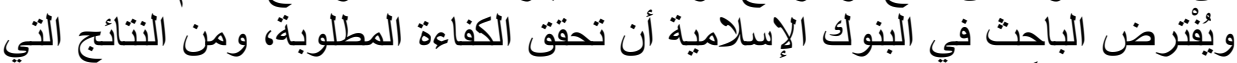

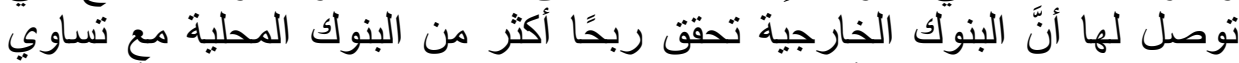

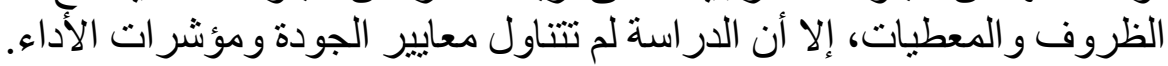

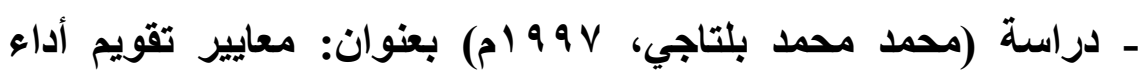
المصارف الإسلامية دراسة نظرية تطبيقية". 
هدفت الدراسة إلى إيجاد معايير لتقويم أداء المصارف الإسلامية للتعرف

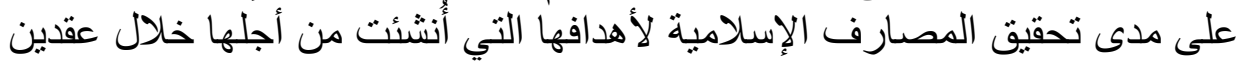

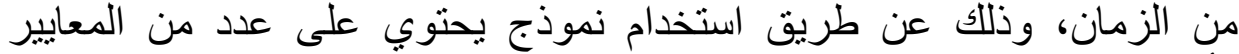
وأدوات القياس وتطبيق ذلك على عينة من المصارف الإسلامية، وقد تبين من

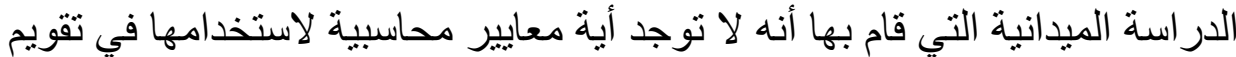
الأداء في المصارف الإسلامية مما حدا بالبنك الإسلامي للتنمية إلى الدعوة الإنها لتكوين

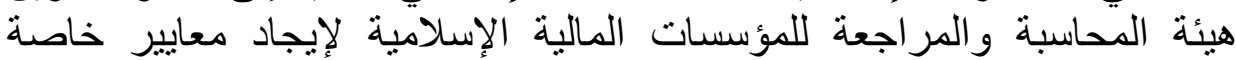

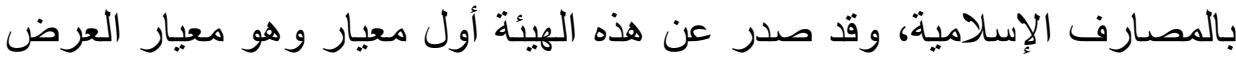

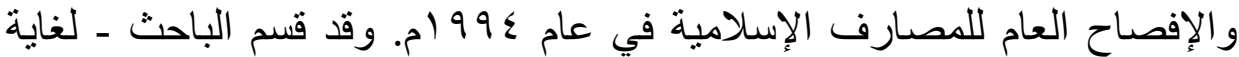

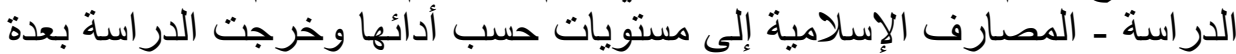

$$
\text { نتائج وتوصيات. }
$$

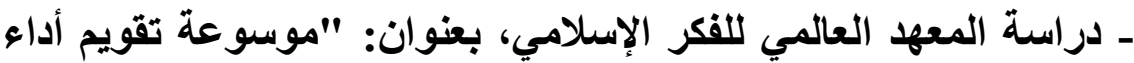

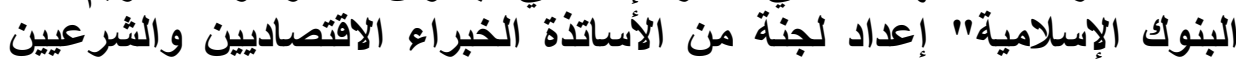

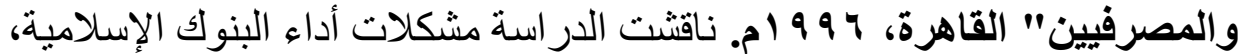

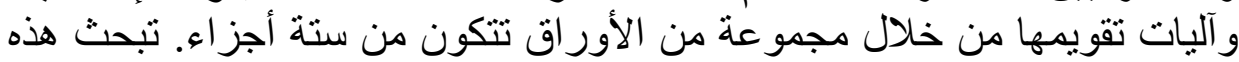

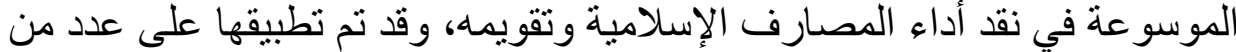

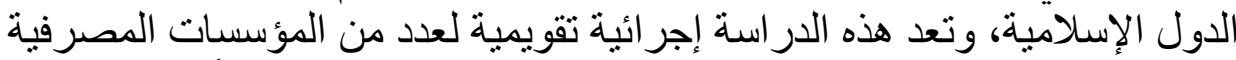

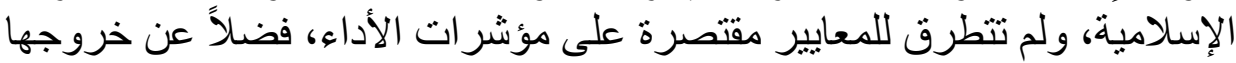

مما سبق يتبين مدى الحاجة لاليل منشود للجودة، يحتوي المعابير ومؤشر ات

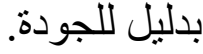
الأداء، و الممارسات الجيدة التي تحقى تللك المعايير.

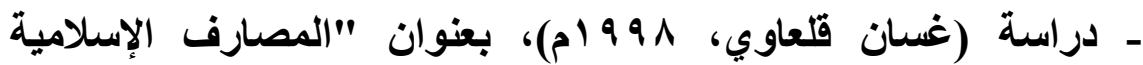

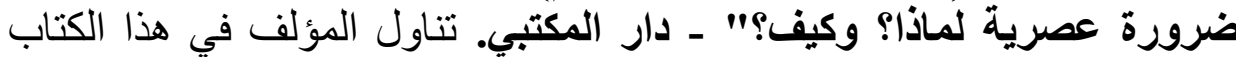

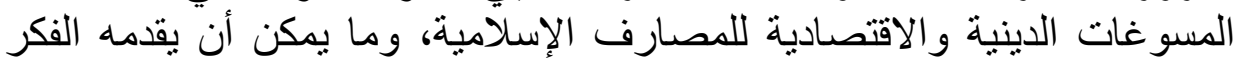

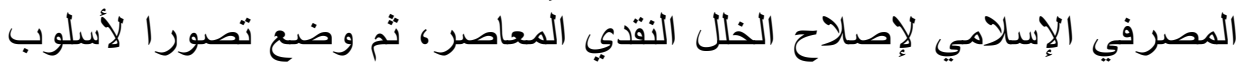

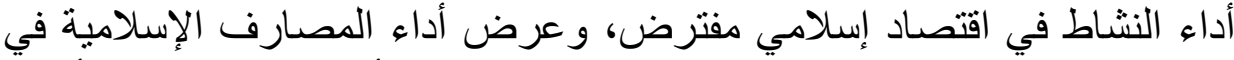

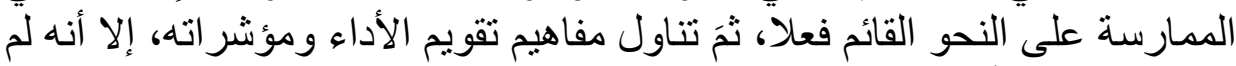

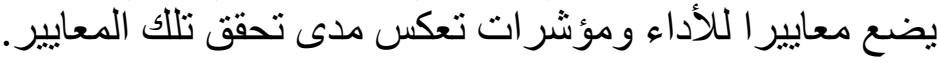

1. خطة الاراسة

المقدمة: وتتضمن الإطار العام للار اسة ويشمل. ـ التمهيد و أهمية الموضون. الإطنوع. 


$$
\begin{aligned}
& \text { ـ ـ أهداف الدر اسة. } \\
& \text { ـ أسباب اختيار الموضوع. } \\
& \text { ـ فرضيات الدر اسة. } \\
& \text { ـ مشكلة الدر اسة. } \\
& \text { ـ ـ منهجية الدراسة. } \\
& \text { ـ ـ الدر اسات السابقة. } \\
& \text { ـ خطة الدر اسة. }
\end{aligned}
$$

9. المفاهيم القتية المستخدمة

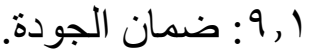

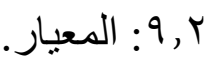

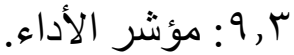

$$
\begin{aligned}
& \text { ع , } 9 \text { الممارسة الجيدة. }
\end{aligned}
$$

و 9 , ضمان الجودة: هو منحى نظامي يسعى للتأكد من أنّ أداء المصارف

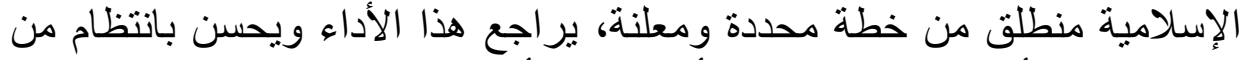

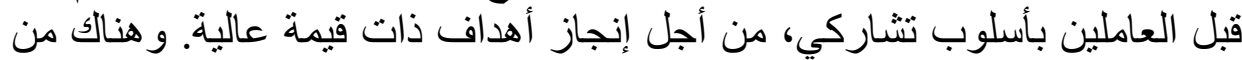

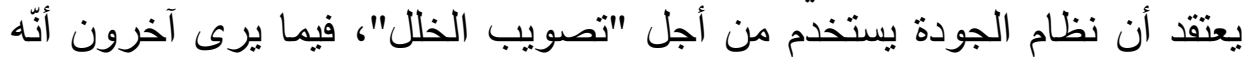

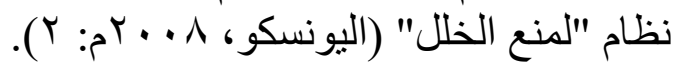

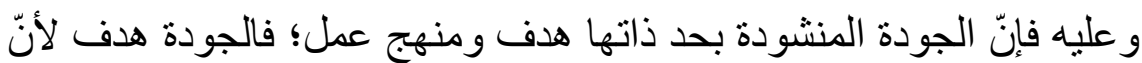

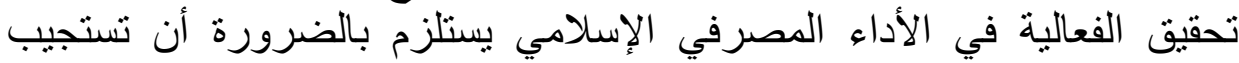

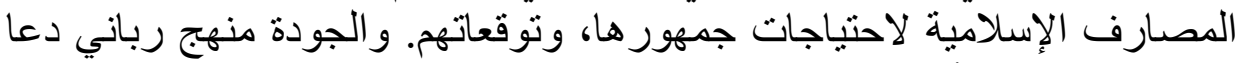
له القرآن الكريم. آ أل

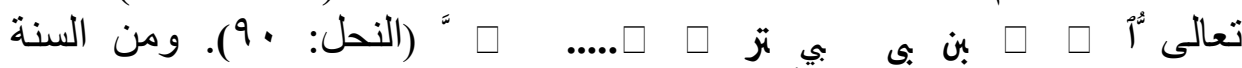

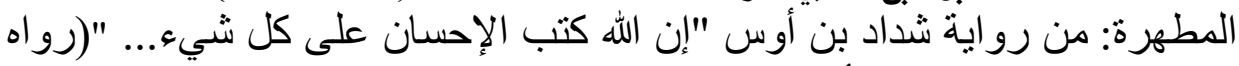

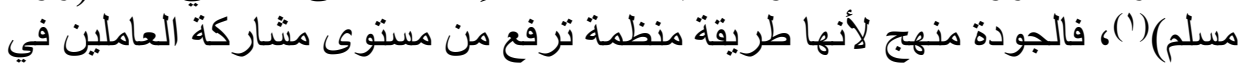
التخطيط للعمل و تتفيذه ومر اجعته وتحسينه و اتخاذ القر ار ات ات المناسبة.

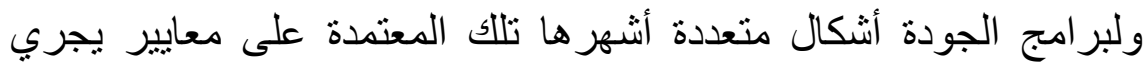
الالتزام بها لتحقيق الهدف، من ذلك المعايير التي طورتها المنظمة التهائ العالمية

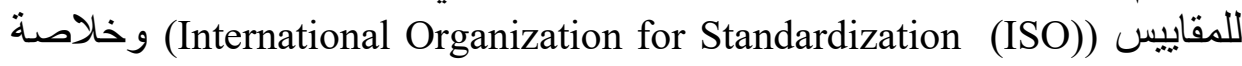

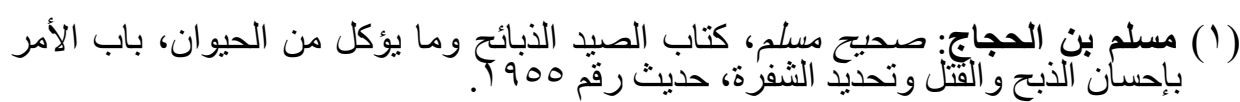


القول إن ضمان الجودة هو منحى نظامي يقوم على بناء الجودة في مكونات النظام

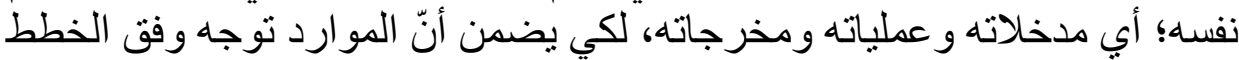

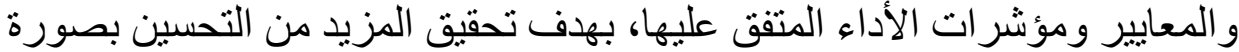
مستمرة، لإنجاز أهداف ذات قيمة عليا للأفر اد وللمؤسئة

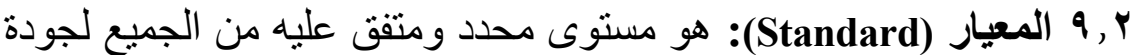

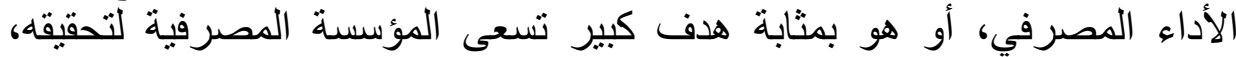

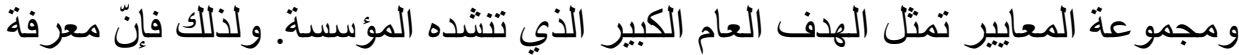
مدى تطبيق المعيار تساعد على ضمان الجودة، كما أنّ مراجعة المعيار تساعد في لهي

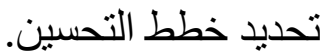

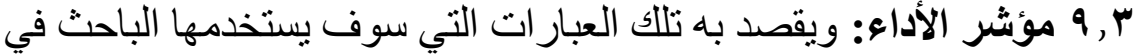

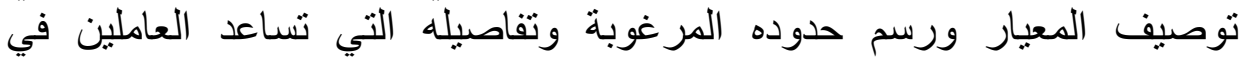

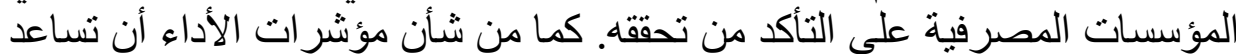

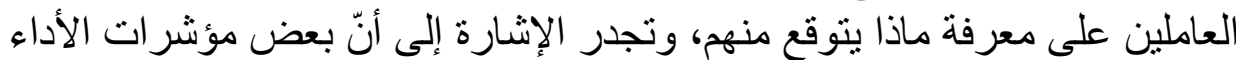

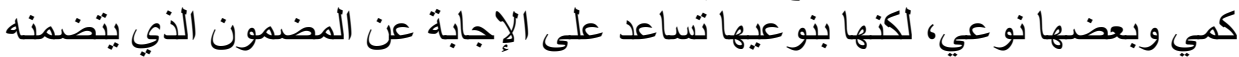

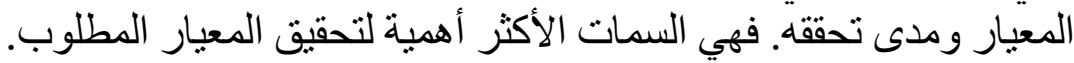

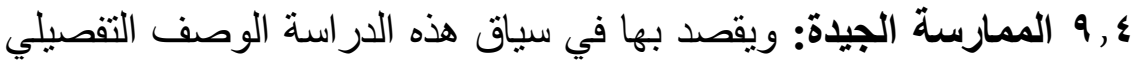

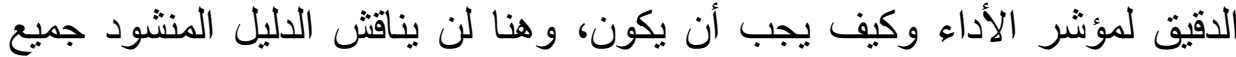

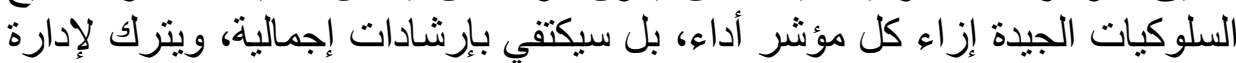

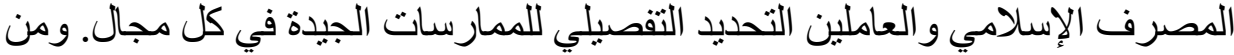
شأن تحديد الممارسات الجيدة أن نوضح ما لئي الئي:

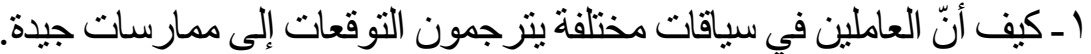

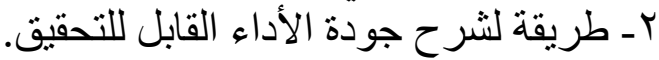

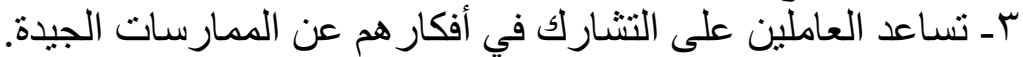

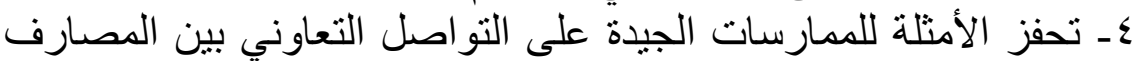

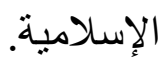
وخلاصة القول فإنّ ضمان الجودة هو هدف تسعى إليه المصرفية

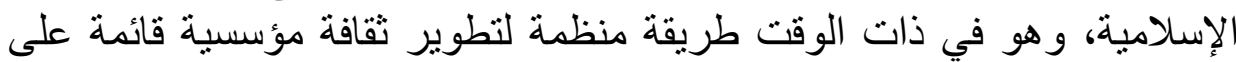
تحسين الجودة بشكل منو اصل.

• 1. وثيقة دليل الجودة للمصارف الإسلامية. وتتضمن هذه الوثيقة المكونات الثالية: 


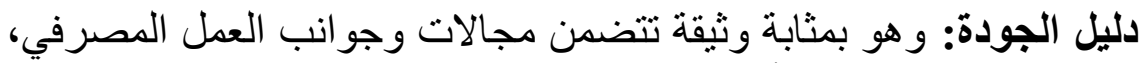

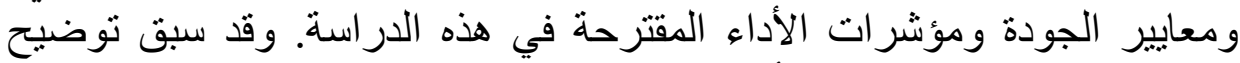

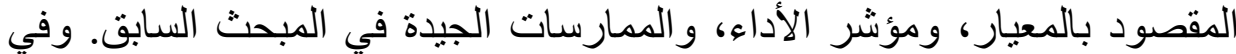

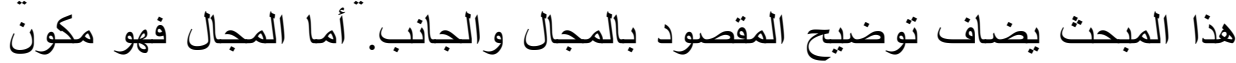
رئيس من مكونات العمل المصرفي الإسلامي مثل: شؤون العاملين، والخدمات

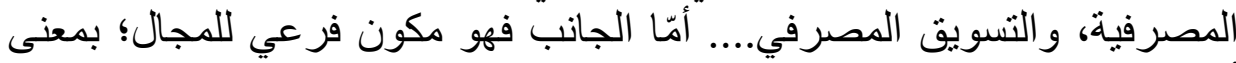
أن المجال يصنف بدوره إلى عدة جوانب فمثلا لو تناولنا مجال شؤون العاملين

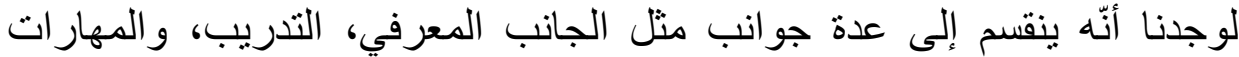
الاجتماعية، ... و غير ذلك.

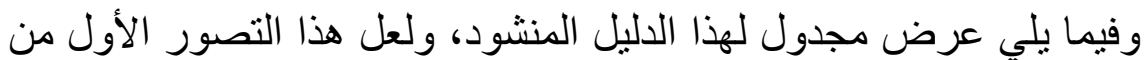

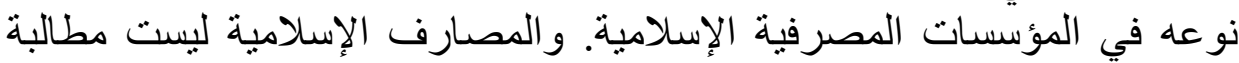
بالعمل على جميع المعايير دفعة واحدة، بل إنها مدعوة لمر اجعة خططها السابقة وممارساتها ثمّ محاكمتها إلى الدليل.

ويعكس هذا الاليل الاتجاهات التطويرية الأحدث في تحسين العمل المصرفي

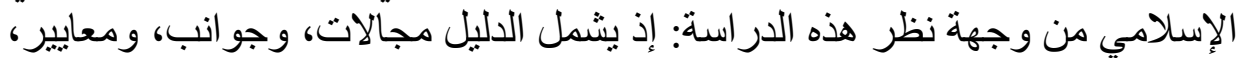

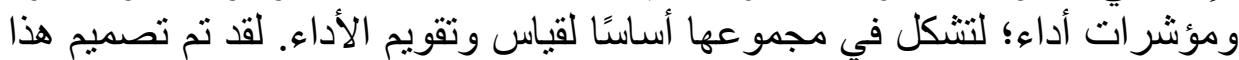

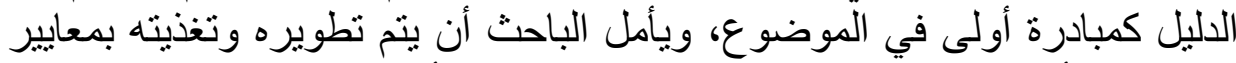

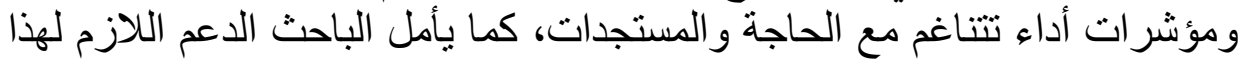

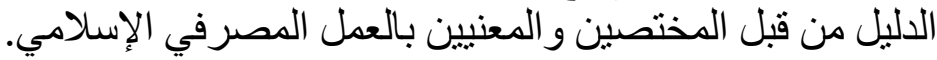

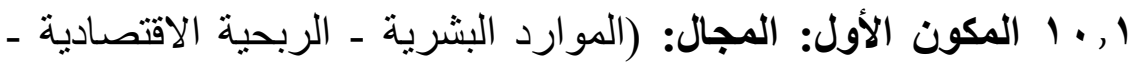

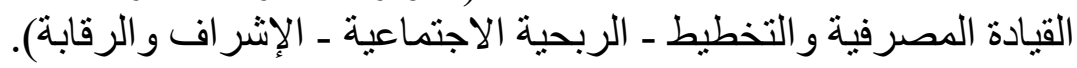
ץ , • ا المكون الثاني: الجاتب: (الجانب الفني_ المعتقدات و المهار ات الفردية

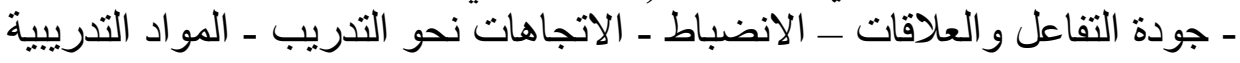

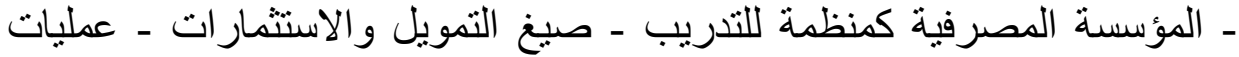

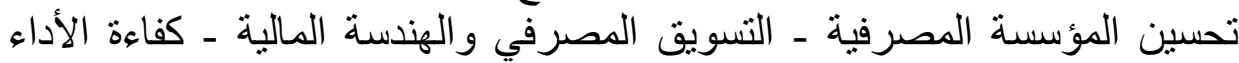
المصرفي ـ التمويل الإنتاجي ـ الزكاة والصدقات والقرض الحسن وتنمية المجتمع

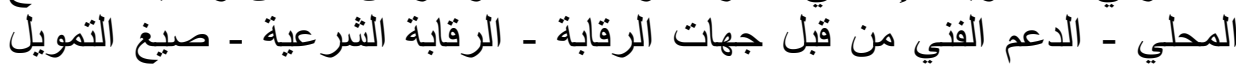
والاستثمار - علاقات المصرف).

r, • • المكون الثالث: معاييز ضمان الجودة:

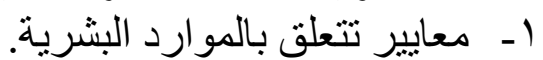
r - معايير تتعلق بالربحية الاقتصادية. 
ك- ــ - معايير تتعلق بالربحية الاجتماعية. ع - معايير تنعلق بالانضباط الثنرعي (المعايير الثرعية للهيئة، دراسة أبو غدة).

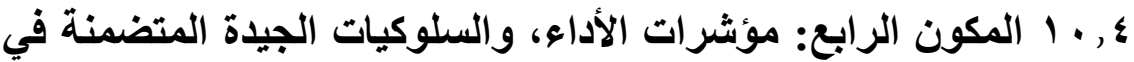

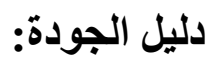

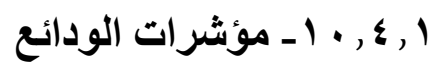

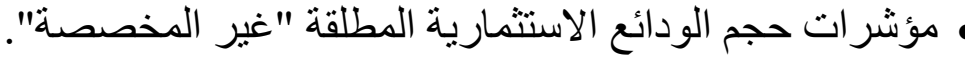
• مؤشر ات حجم الودائع الاستثمارية المقيدة وصناديق الإئ الاستثمار.

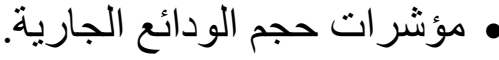

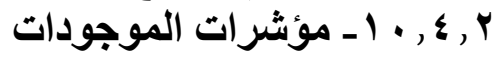
• مؤشر ات حجم الموجودات الموات المستثرة. • مؤشر ات الموجودات الإجمالية. • مؤشر ات استثمار ات الودائع المقيدة وصناديق الاستثمار. • مؤشرات الموجودات النقية و المصرفية.

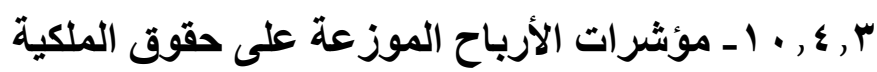
• مؤشر ات كفاءة النفقة في تحصيل الإير ادادات.

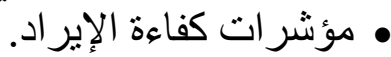
• مؤشر ات الربح الصافي إلى حقوق الملكية. • تأثير التغير في حقوق الكلكية على تطور ربحيتها.

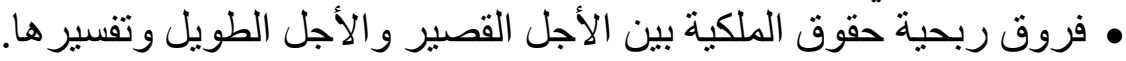
• تأثير الودائع الجارية على ربحية حقوق الملكية.

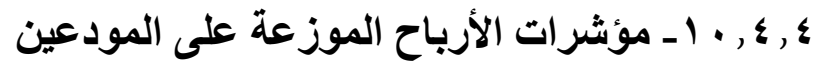

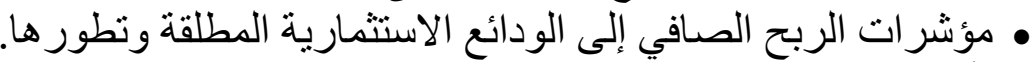

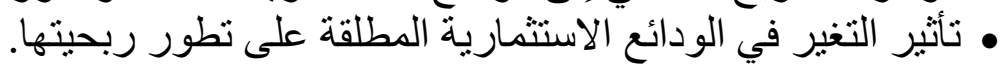

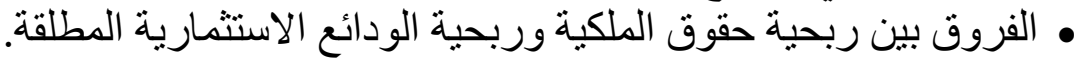

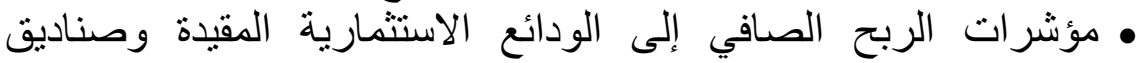
الاستثمار ومؤثر اتها.

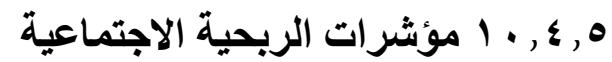

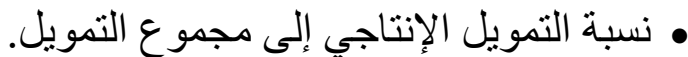
• • نسبة تمويل المشرو عات الصنيل الصغيرة إلى مجموع التهيل التمويل. • نسبة تمويل السلع الاستهلاكية المعمرة (بما فيها السكن). 


$$
\text { • مؤشر القرواة والصدقات. }
$$

\begin{tabular}{|c|c|c|c|}
\hline مؤشرات الأداءـ السلوكيات الجيدة & 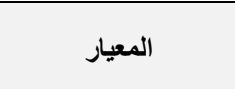 & $\overline{\bar{j}}$ & $\overline{3}$ \\
\hline 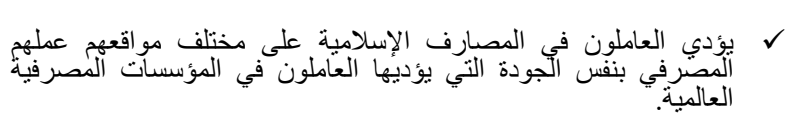 & 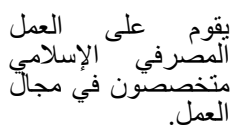 & $\begin{array}{l}\bar{y} \cdot \bar{y} \\
\bar{y} \cdot \bar{y}\end{array}$ & \\
\hline 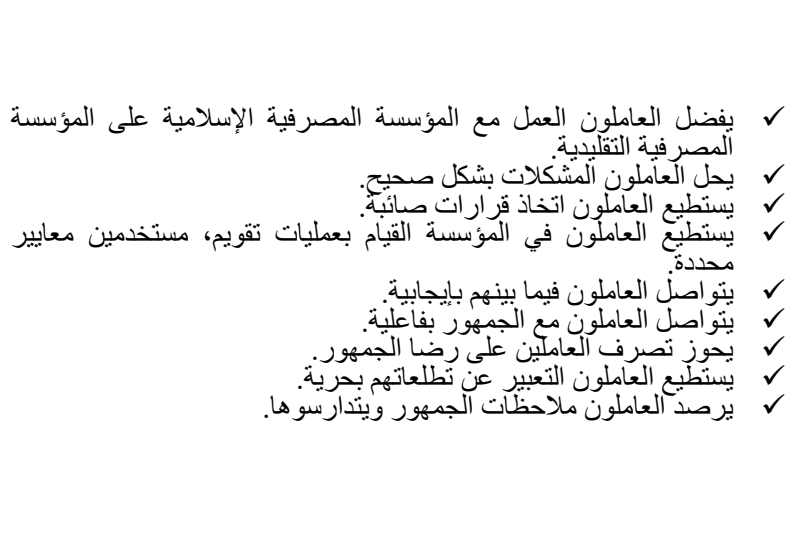 & 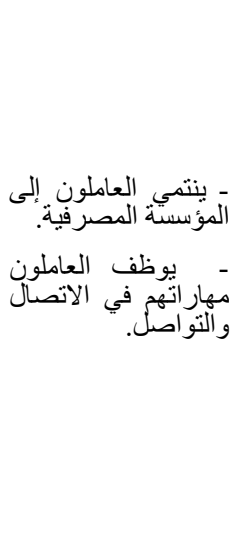 & 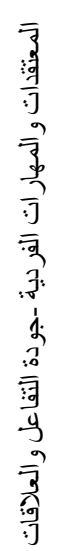 & $\begin{array}{l}\overline{3} \\
\overline{7} \\
\overline{3} \\
\overline{3} \\
. \overline{3}\end{array}$ \\
\hline 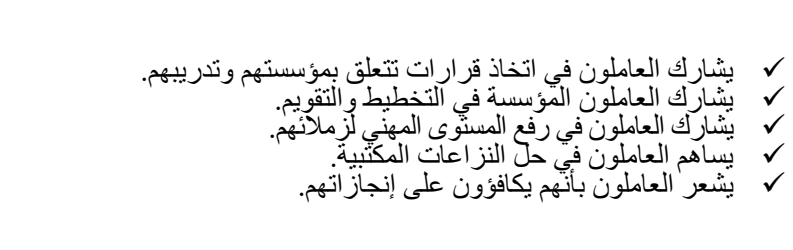 & 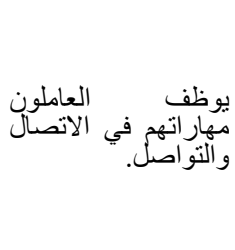 & 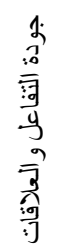 & \\
\hline 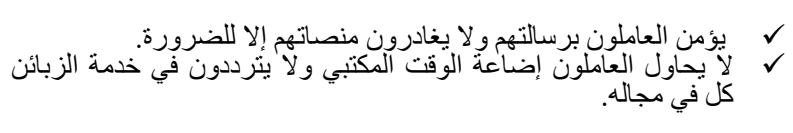 & 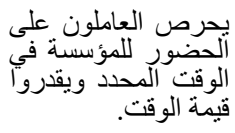 & ד. & \\
\hline 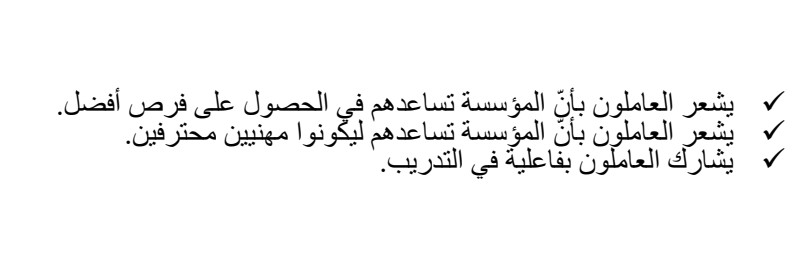 & 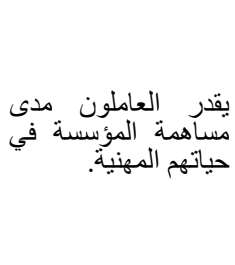 & 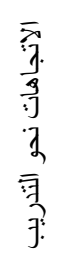 & $\frac{7}{3}$ \\
\hline
\end{tabular}




\begin{tabular}{|c|c|c|c|}
\hline مؤشرات الأداءــ السلوكيات الجيدة & المعيار & $\overline{\bar{j}}$ & $\overline{3}$ \\
\hline 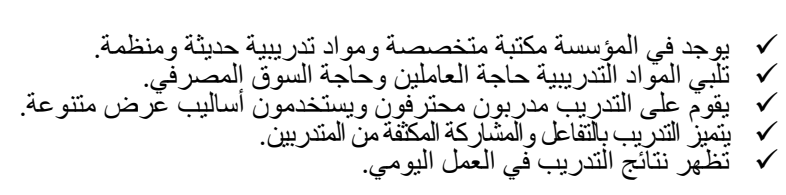 & - & 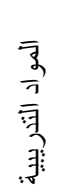 & \\
\hline 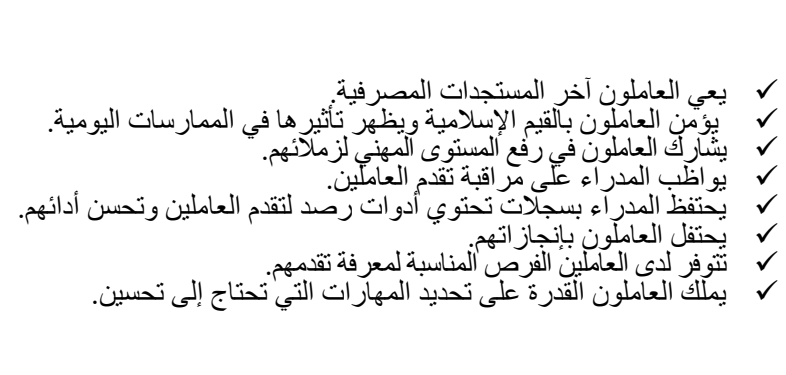 & 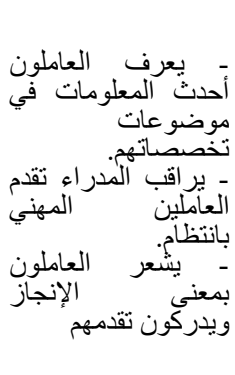 & 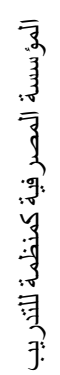 & $\begin{array}{c}\overline{3} \\
\overline{7} \\
\overline{3} \\
.7\end{array}$ \\
\hline
\end{tabular}




\begin{tabular}{|c|c|c|c|}
\hline مؤشرات الأداء- السلوكيات الجيدة & 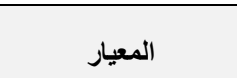 & 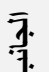 & \\
\hline 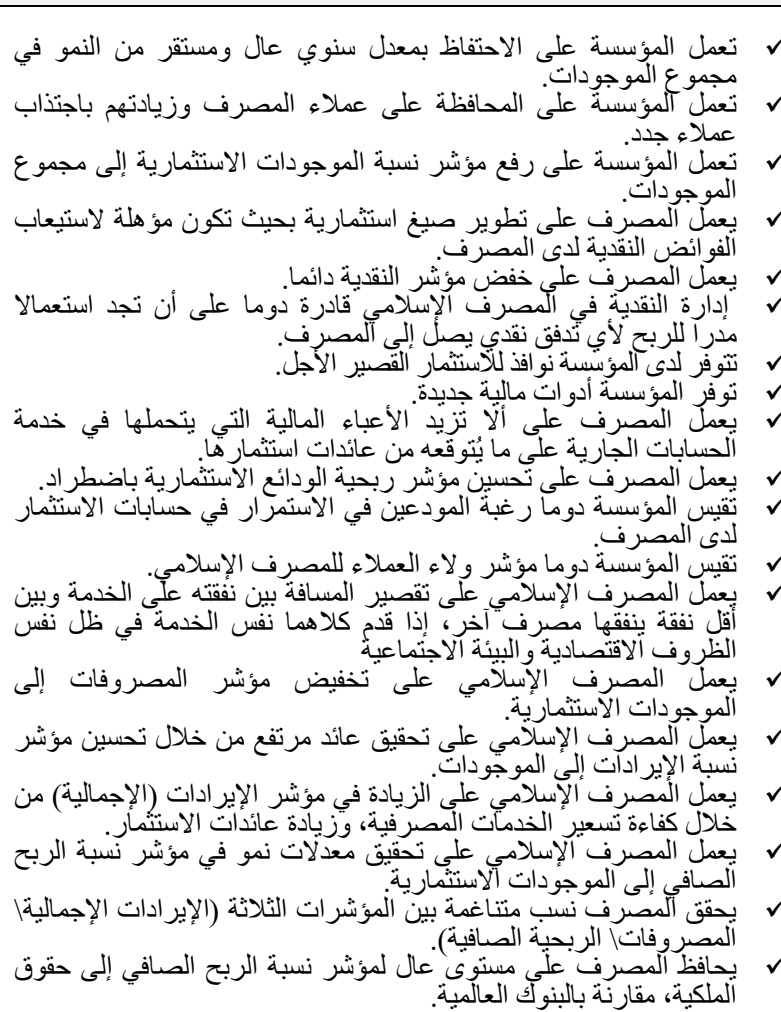 & 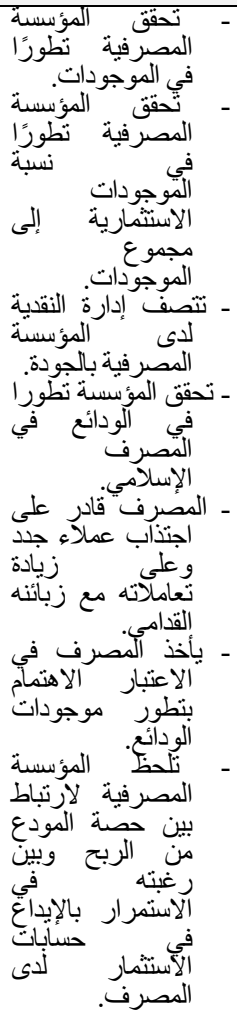 & 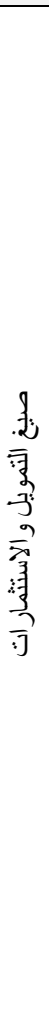 & 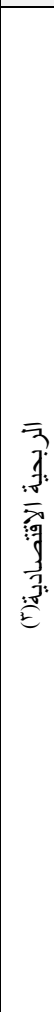 \\
\hline
\end{tabular}

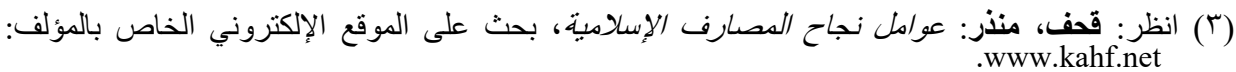




\begin{tabular}{|c|c|c|c|}
\hline ت الجيدة & المعيار & 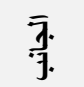 & $\overline{\bar{z}}$ \\
\hline 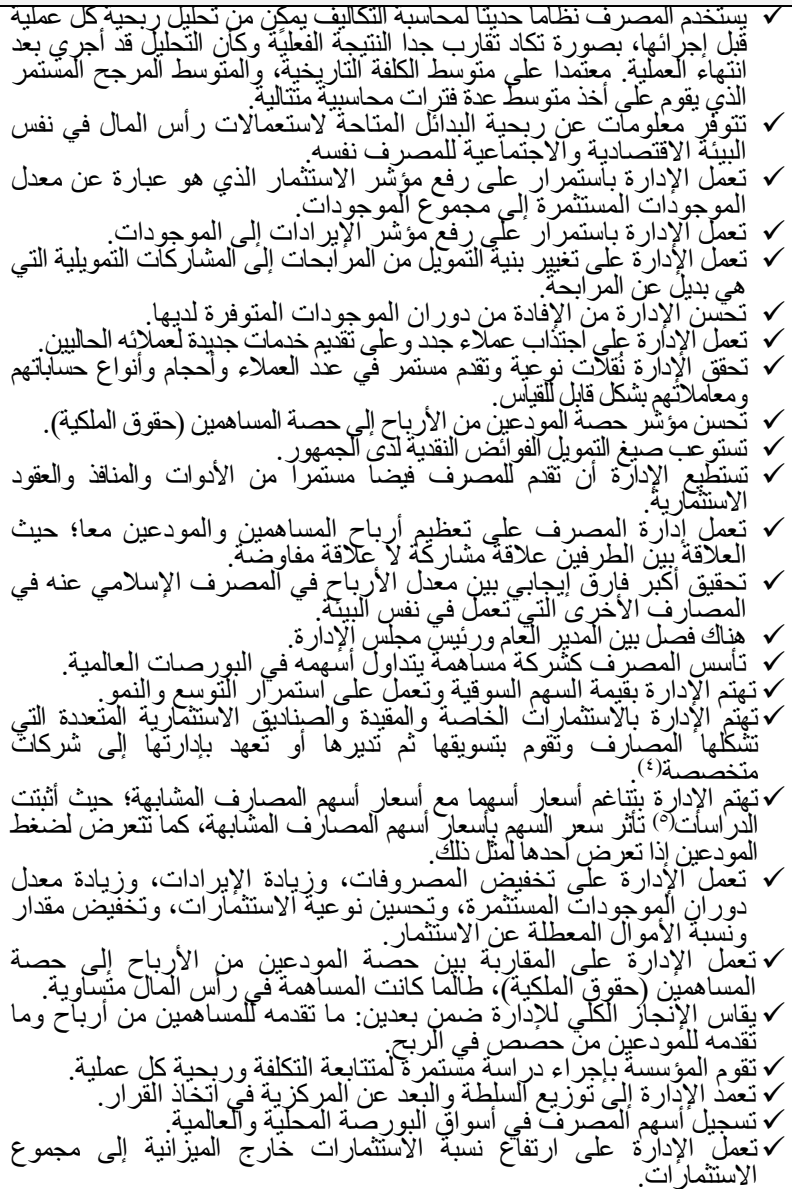 & 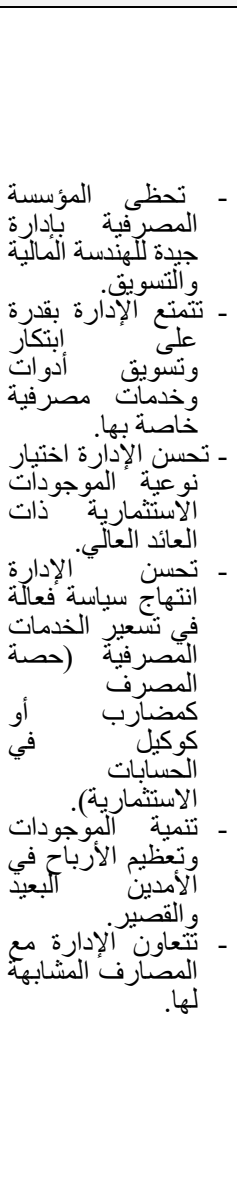 & 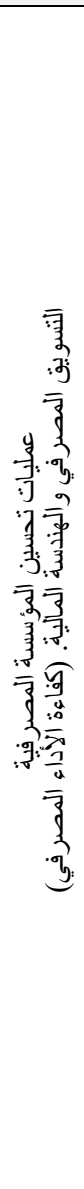 & 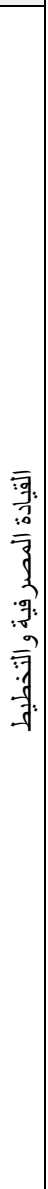 \\
\hline
\end{tabular}

(4) Ihsan Isik and M. Kabir Hassan, "Cost and Profit Efficiency of the Turkish Banking Industry" Financial Review, Vol. 37, No. 2, May 2002, pp. 257-280.

(5) Robert Schweitzer, Samuel H. Szewizyk and Raj Varma, "The Effect of Bank Debt Downgrades on Stock Prices of other Banks," Financial Review, Vol. 36, No. 4, Nov. 2001, pp. 139-156. 


\begin{tabular}{|c|c|c|c|}
\hline مؤشرات الأداء- السلوكيات الجيدة & المعيار & $\overline{\bar{y}}$ & $\overline{3}$ \\
\hline 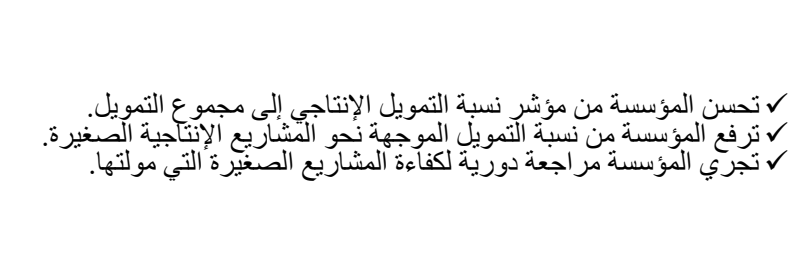 & 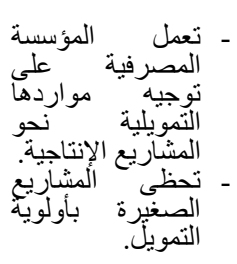 & 舟 & 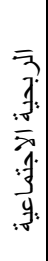 \\
\hline 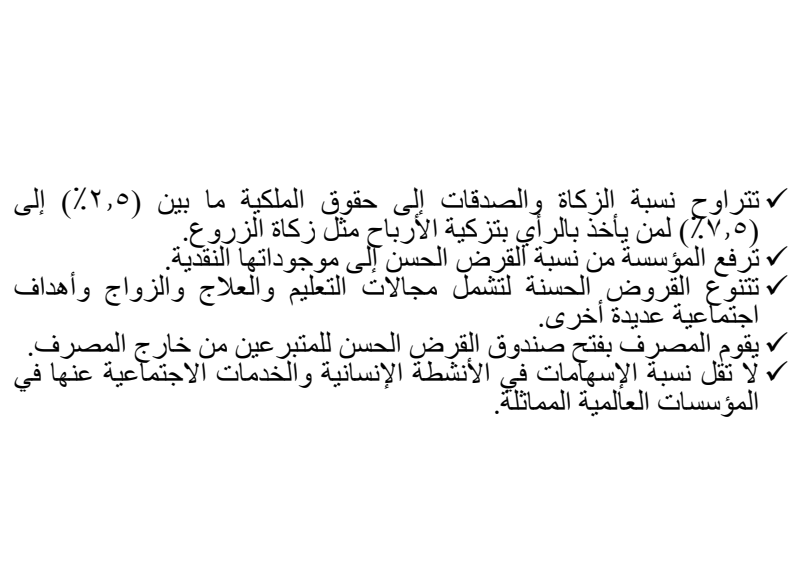 & 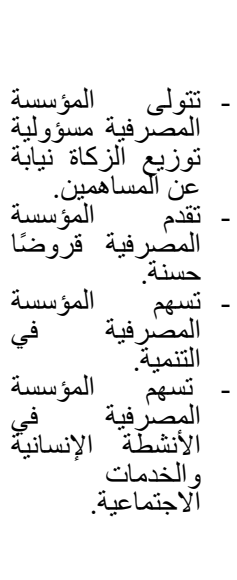 & 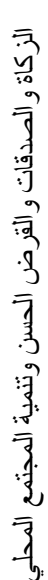 & 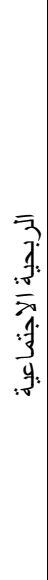 \\
\hline 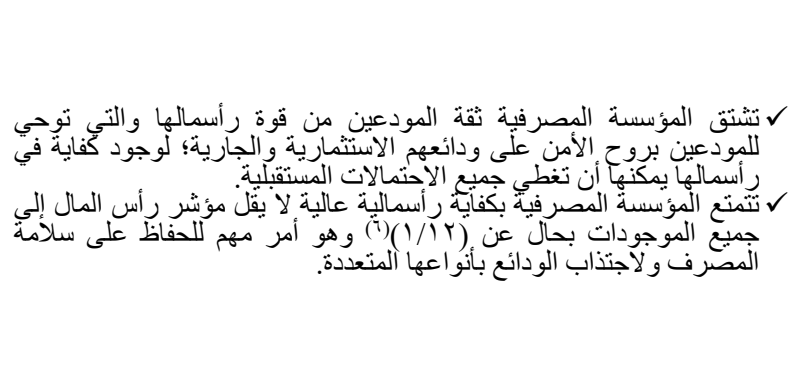 & - & 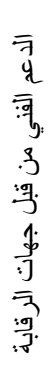 & 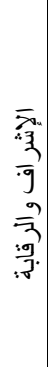 \\
\hline
\end{tabular}




\begin{tabular}{|c|c|c|c|}
\hline مؤشرات الأداء- السلوكيات الجيدة & المُ & $\overline{\mathrm{j}}$ & $\overline{3}$ \\
\hline 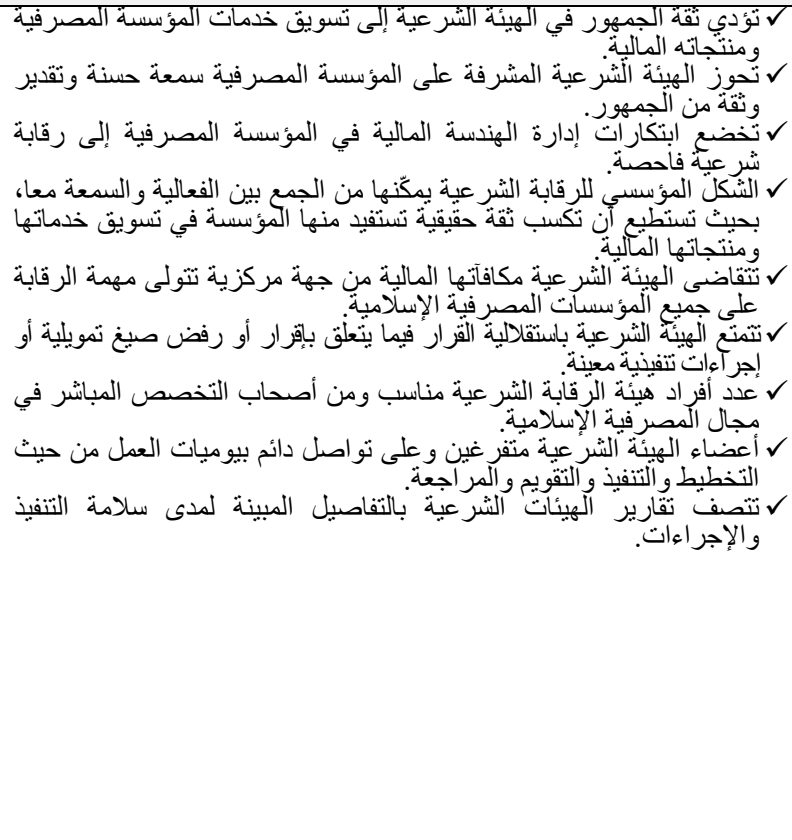 & 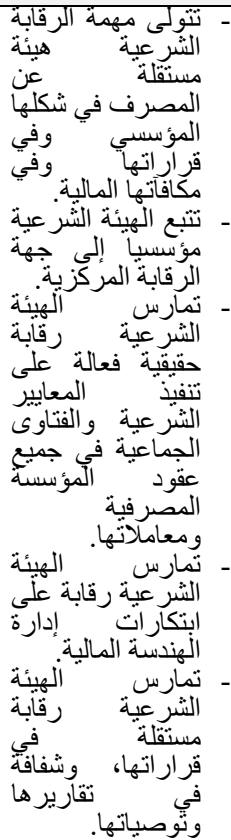 & 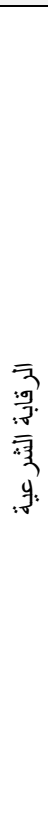 & 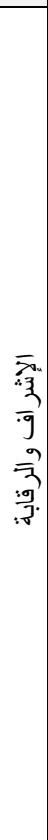 \\
\hline
\end{tabular}




\begin{tabular}{|c|c|c|c|}
\hline مؤشرات الأداء- السلوكيات الجيدة & المعيا: & 可. & \\
\hline 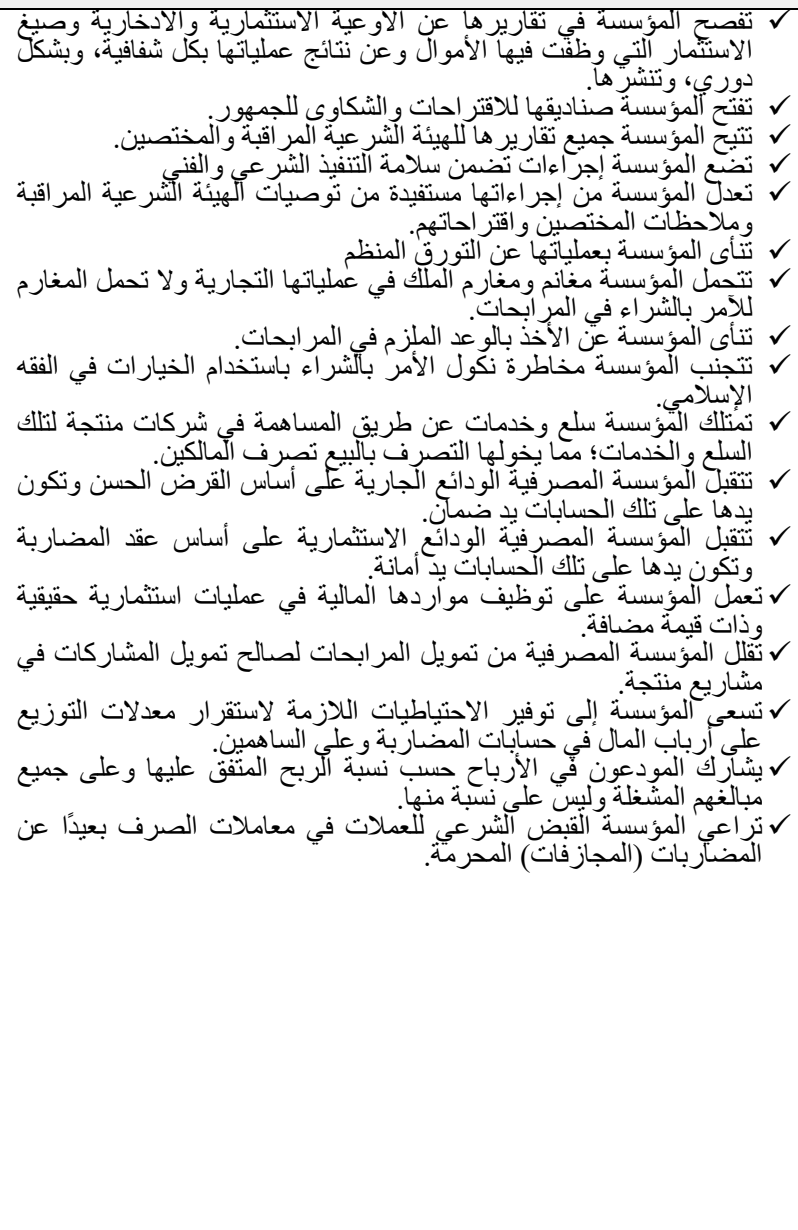 & 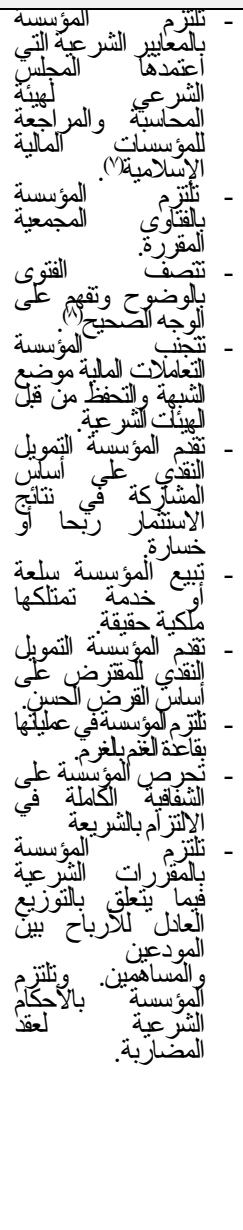 & 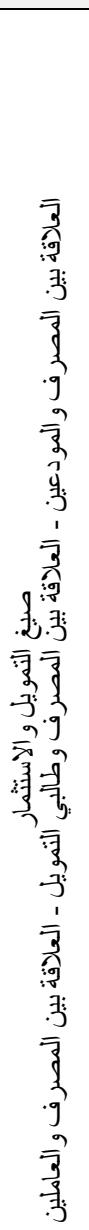 & $\begin{array}{c}\overline{7} \\
\overline{7} \\
\overline{7} \\
\overline{3} \\
\frac{y}{3}\end{array}$ \\
\hline
\end{tabular}

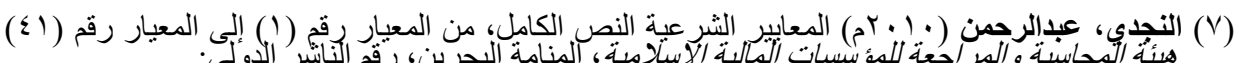

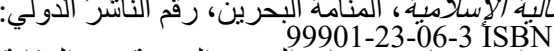

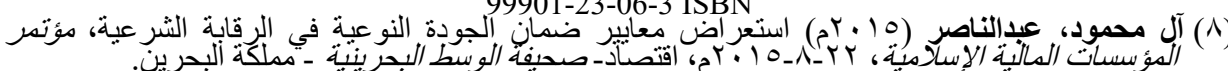


توصل الباحث إلى تقديم إطار لضمان جودة المصارف الإسلامية في مجالات

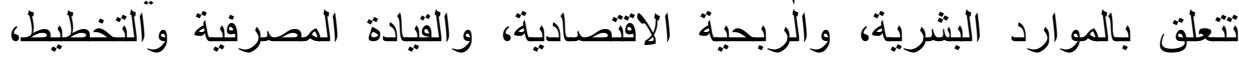
والربحية الاجتماعية، وكذلك في مجال الإشراف والرة الرقابة. وقد أضافت الدراسة

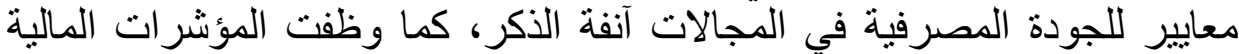

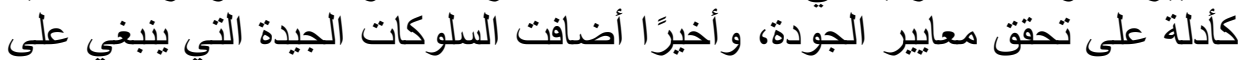

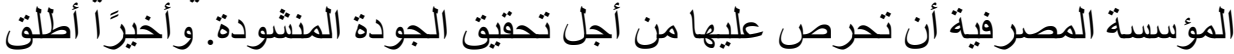
الباحث على هذا الإطار "دليل جودة المصارف التهن الإسلامية".

- توصي الدراسة الباحثين المختصين في هذا المجال بتطوير هذا الدليل؛ التوصيات بإضافة معايير جديدة ومؤشرات أداء إضافية ترتقي بهذا الدليل إلى مستوى دليل

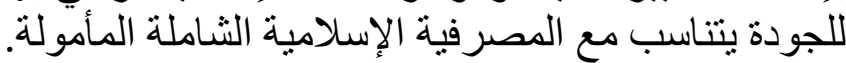

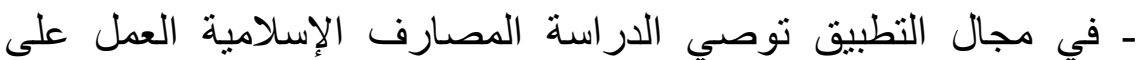
تطوير أدائها بالجودة المطلوبة والإسهام في تطوير هذا النموذج المقتر ح.

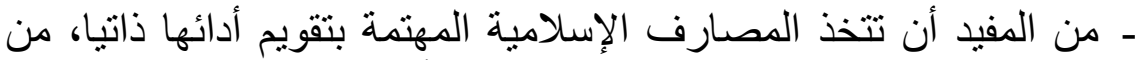

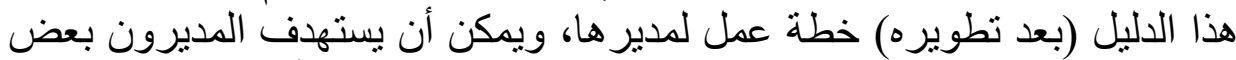
المعايير في كل فترة زمنية؛ حيث يقوم المدير المعني بتقويم الأداء باختيار المعيار

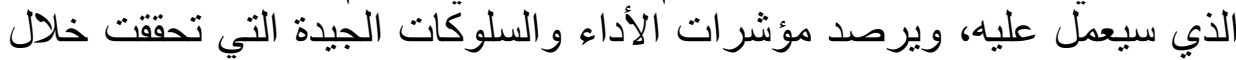

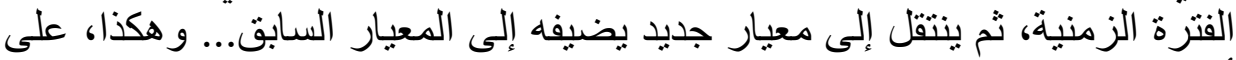
أن تبقى المعايير السابقة مستهدفة كمشروع دئمة دائم للجودة.

- يمكن إضافة معايير أخرى تستهدف جميع جوانب العمل المصرفي من قبل الإنل

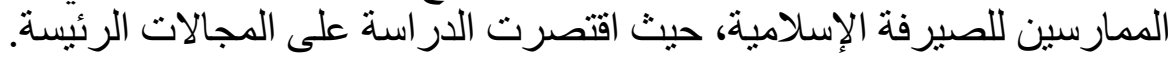

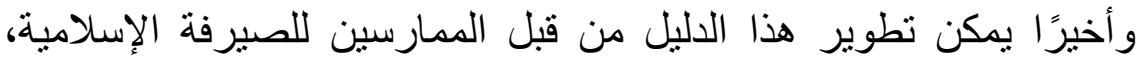

وذللك بإعطاء أوز ان ترجيحية لمؤشر ات الأداء؛ بحيث يكون التقويم الذاتي كميًا.

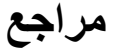

أولا: باللغة العربية

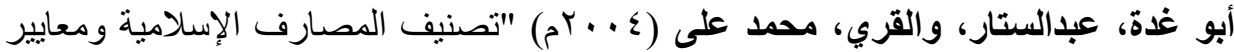

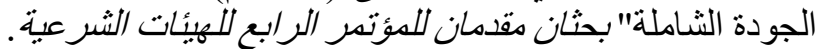

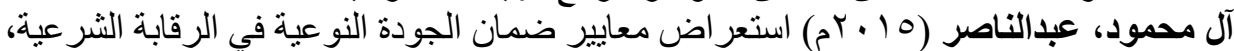

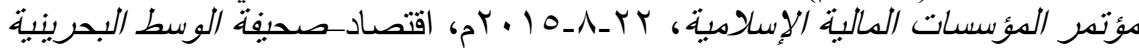

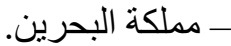

بلتاجي، محمد محمد (99 (9 ام) معايير تقويم أداء المصارف الإسلامية دراسة نظرية تطبيقية، رسالة دكتوراه غبر منشورة، جامعة الأزهر كلية التجارة. 


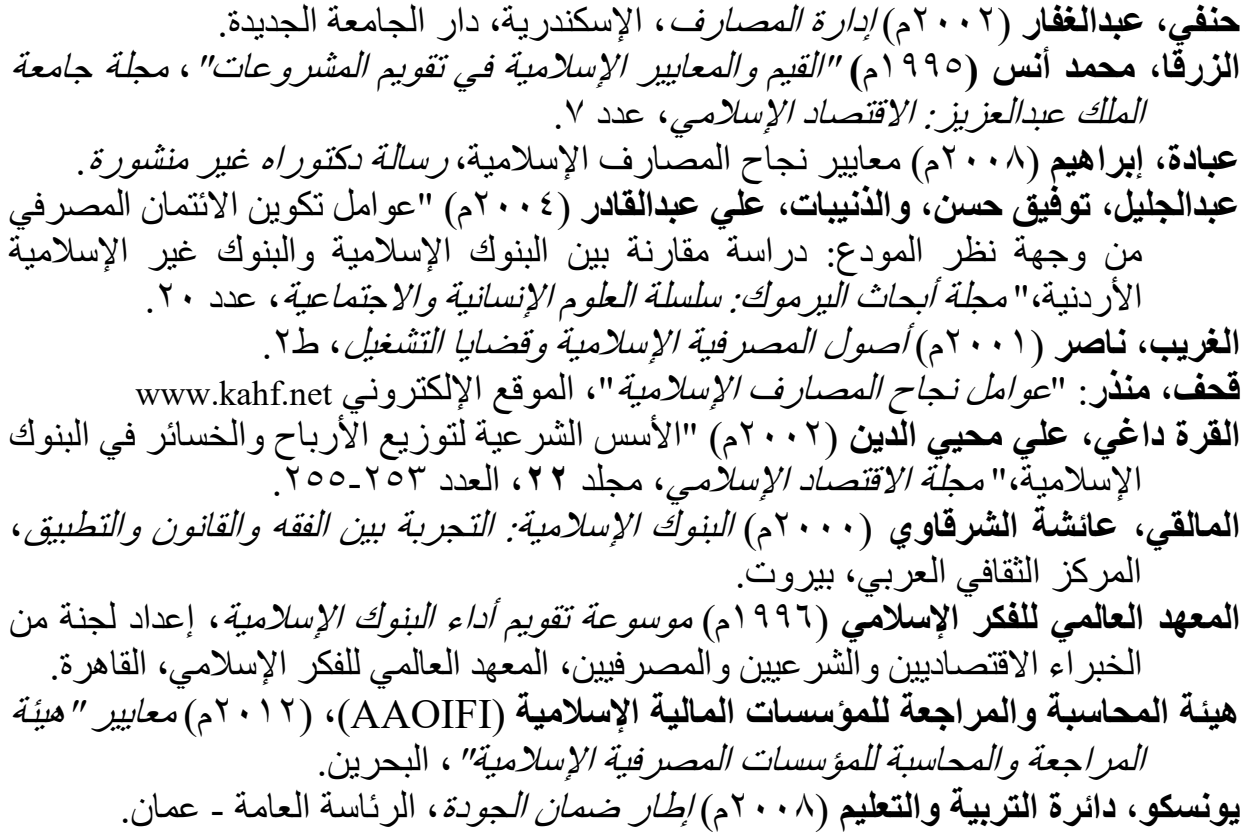

ثانيا: باللغة الإنجليزية

Bashir, Abedl Hameed M. Assessing the Performance of Islamic Banks: Some Evidence from the Middle East, Bashirah@alphao.gram.edu

Beitman, Artford (1990) Financial Services Marketing Proven Techniques for Advertising, Direct Mail and Telemarketing, Liberty Hall Press, Ridge Summit, PA.

Berry, Leonard L. David R. Bennett and Carter W. Brown (1989) A Profit Strategy for Financial Institutions, Dow Jones-Irwin, Homewood, Ill.

Gackle, Merlin (1994) Bankers as Brokers: The complete guide to selling mutual funds and other fee-based investment products, Probus Publication Co., Chicago, Ill.

Graddy, Duane B. and Austin H. Spencer (1990) Managing Commercial Banks: Community, Regional, and Global, Prentice Hall, Englewood Cliffs, N.J.

Gray, Janet L. and Thomas W. Harvey (1992) Quality Value Banking Effective Management Systems, J. Wiley, New York.

Grubbs, Ray M. and Reienbach, R.E. (1991) Customer Service Renaissance, Bankers Publishing Co, Chicago, Ill.

Hendershott, Robert J. Darrell E. Lee and James G. Tompkins (2002) "Winners and losers as Financial Service Providers Converge," in the Financial Review, 37(1), Feb.

Iqbal, Munawar (2001) Islamic and conventional banking in the nineties, Islamic economic studies, $\mathbf{8}(2)$.

Isik, Ihsan and M. Kabir Hassan (2002) "Cost and Profit Efficiency of the Turkish Banking Industry” in Financial Review, 37(2), May, pp. 257-280. 
Prindl, Andreas R. and Bimal Prodhan, ed., (1994) Ethical Conflicts in Finance, Blackwell Finance, Oxford, UK and Cambridge, Mass.

Reidenbach, Eric and M. Ray Grubbs (1987) Developing New Banking Products: A Manager's Guide, Prentice-Hall, Englewood Cliffs, N.J.

Schweitzer, Robert Samuel H. Szewizyk and Raj Varma (2001) "The Effect of Bank Debt Downgrades on Stock Prices of other Banks" Financial Review, 36(4), Nov.

Stanic, Vlad and Denis Boyle, ed., (1999) Developing People and the corporate culture in financial services, CRC Press, Boca Raton, Fla.

Taylor, Jeremy F. (1994) The Prudent Management of Modern US Banks, Quorum Books Publishing Co., London \& Connecticut.

Thornhill, William T. Risk Management for Financial Institutions: Applying CostEffective Controls and Procedures, Bankers Publishing, Rolling Meadows, Il.

Yudistira, Donsyah (2004) Efficiency in Islamic Banking, an Empirical Analysis of Eighteen Banks, Islamic economic studies, 12(1).

\title{
Quality Assurance Performance \\ Guide for Islamic Banking
}

\author{
Adnan A.M. Oweida
}

Researcher at ZAYED University, IIWS

Adnan.Oweida@ZU.ac.ae 
Abstract. This research explores the development a quality assurance guide for Islamic banking performance. The researcher has prepared the quality assurance index for Islamic banking. The guide consists of many parameters like quality standards and performance indicators. The study aims to provide Islamic banks with the quality assurance guide as a self-correction and assessment of the business that these institutions carry out. Thus, the guide works like as a work's plan or a systematic domain seeking for making sure that, Islamic banks performance go throw a specified and well-designed plan to help them satisfy the stakeholders of their business and industry. It has to be stressed that the guide is still in its preliminary stages; therefore any feedback is more than welcomed to improve its shape and substance.

Keywords: Standards of quality assurance, Performance indicators, the Good practices, Quality assurance index for Islamic Banking 


\section{د. عدنان عويضية}

أستاذ مساعد في الاقتصاد والمصهارف الإسلامية، عمل خبيرًا تربويًا في البرنامج التعليمي للأمم المتحدة، وعمل عضو هيئة تدريس في كلية الاقتصاد وادياد

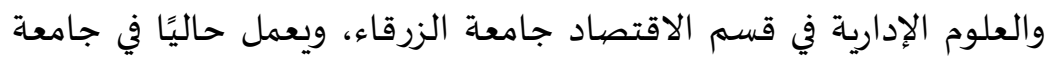

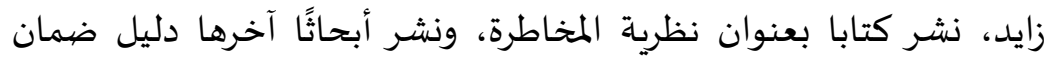

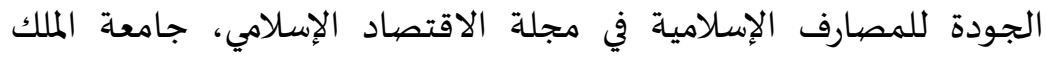

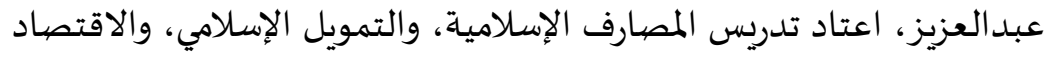
الجزئي والكلي، والمالية العامة. البريد الإلكتروني: Adnan.Oweida@ZU.ac.ae 